\title{
Optimization of the steel frame elements sections formed by $i$-beams diagonal expansion
}

\author{
Sergey Schutsky*, S.V. Korzhov, A.S. Boldyrev \\ Don State Technical University, Rostov-on-Don, 344002, Russia
}

\begin{abstract}
The article deals with the design of steel frames with the elements of variable stiffness, formed by the $I$-beam walls dissolution along the diagonal and subsequent welding. The possibility of rolled $I$ beams with different profiles optimal use along Industry Standard Association of Enterprises and Organizations for Standardization of Ferrous Metallurgy Products 20-93, for the frame pre-fabricated elements is determined. A calculation algorithm for determining the geometric characteristics of a composite section is presented. The analysis of such elements use effectiveness is carried out, using the example of the building frame, designed according to the frame-link scheme of welded single-span frames with variable section elements in accordance with the standard typicals $828 \mathrm{KM}$.
\end{abstract}

\section{Introduction}

One of the main and urgent problems of modern engineering and applied research is resource conservation, which is of direct practical importance for the construction industry and economy of the Rostov region.

There is currently a decrease in the volume of housing construction, against the background of which the industry is recovering at an accelerating pace. The most popular in the construction industry are the industrial and warehouse buildings [10].

Due to the fact that the most common structural scheme of industrial and warehouse buildings is a metal frame made of architraves with an appropriate system of horizontal and vertical ties, the work considers the optimal options for designing steel frames from Ibeams of variable stiffness.

Buildings with variable cross-section frames are produced today in the Russian Federation by many factories provided with the equipment for cutting and assembling Ibeams. The most widespread use is found for single-span frames with the spans from 12 to $36 \mathrm{~m}$ with hinged support of the struts on the foundation and rigid coupling of the girder with the extreme struts.

Domestic and foreign design practice offers the following options for designing such frames: 1) use of I-beams with a perforated wall as racks and crossbars; 2) use of I-beams with corrugated walls as posts and crossbars; 3 ) use of I-beams with fluted web as posts and crossbars; 4) the use of welded I-beams with a wall of variable height as racks and

\footnotetext{
*Corresponding author: svpike1@rambler.ru
} 
crossbars; 5) use as racks and crossbars of frames of rolling I-beams of variable height, formed from ordinary I-beams by diagonal opening of the walls with subsequent welding.

\section{Materials and methods}

A frame with the use of frames made of rolled I-beams of variable height, formed by dissolving and subsequent welding of the walls of ordinary I-beams, was selected as the research subject.

The main stage in the design of frames from transverse frames of variable cross-section is the static analysis of structures for the external loads action. In addition to the tasks of static analysis, at this stage, the search for the effective geometry of frames, optimal distribution of stiffness, optimization of sections and manufacturability is carried out $[2,11$, 12]. To reduce the frame structures mass, a number of the researchers in the field of designing frames with variable stiffness recommend increasing the bending stiffness of the sections by increasing their height at the points of action of bending moments with maximum gradients, for example, in the area of the eaves frame node [1]. This technique gives a possibility to redistribute the bending moments in the interface zone of the struts and crossbars of the frame, unloading the frame spans, which makes it possible to reduce the metal consumption and deformability of these frames.

Studies in the field of $I$-sections optimal sizes selection $[3,4]$ have established that the determining factor influencing the bent $I$-beams efficiency is the height of the section and the wall flexibility. This work does not consider I-beams, the work of the wall of which occurs in the supercritical stage, since a stable wall is used in rolling I-beams, the maximum flexibility of which, as a rule, does not exceed 150 [5].

In frames of variable cross-section, the maximum normal stresses in the chords from the longitudinal force and bending moment act over sufficiently long sections. When such frames operate in the elastoplastic stage, plastic deformations can propagate along a considerable length of the element, which can lead to the collapse of the entire structure. Therefore, the norms [6] regulate the restrictions on the plastic deformations development in the frame sections, as a result of which such frames are calculated in the elastic stage. In particular, this is expressed in the ignorance of the coefficient $c_{x}$, taken from the Table 1 [6] depending on the ratios of the areas of the flanges and walls of the calculated $I$-beams. Within the framework of this work, it is proposed that such stresses arise only in the eaves zone of the frame; therefore, it is permissible to take into account the work of $I$-beams in the elastoplastic stage in the span sections of variable cross-section frames.

To set the dimensions of this zone in a numerical value, we introduce a parameter that determines the longitudinal force contribution to the stress-strain state of the frame element.

Under the action of a bending moment $M$ and longitudinal force $N$ in the compressed flange of the $I$-beam, stresses arise, equal in sum to steel resistance:

$$
\sigma_{N}+\sigma_{M}=R_{y}, \frac{N}{A}+\frac{M}{W}=R_{y}
$$

where $W$ and $A$ define the resistance moment of the considered flange and the total $I$ beam area.

From this formula, the required moment of resistance can be expressed: 


$$
W=\frac{M}{R_{y}} \cdot \frac{1}{1-\frac{N}{A \cdot R_{y}}}
$$

Introducing $M / R_{y}$ as $W_{M}$ - the required moment of the section resistance in the absence of longitudinal force, the expression (1) is written as follows:

$$
W=W_{M} \cdot \frac{1}{1-\frac{\sigma_{N}}{R_{y}}}
$$

There is a possibility to express the parameter that determines the fraction of the stress from the longitudinal force $\psi=\frac{\sigma_{N}}{R_{y}}$ from this equation. When this parameter's value is close to 0 , it is rational to take into account the section work in the simplified stage.

The optimal section height of the bent I-beam is found according to the well-known formula [5]:

$$
h_{o p t}=\sqrt[3]{\frac{3}{2} \cdot W \cdot \lambda}
$$

where $\lambda=h / t$ is $I$-beam wall flexibility.

Finite transformations of this formula, including the parameter $\psi$, in particular, reflected in the monograph [1], are as follows:

$$
h_{o p t}=\sqrt[3]{\frac{3}{2} \cdot \frac{W_{M} \cdot \lambda}{1-\psi}}
$$

It follows from the formula that the optimal height of the I-beam is increased when the compressive force acts on it in proportion to the parameter $\sqrt[3]{\frac{1}{1-\psi}}$. In fact, the compressive longitudinal force leads to a displacement of the neutral axis of the section and an increase in the height of the compressed zone of the wall, which negatively affects its local stability.

The studies on the displacement values dependence of the neutral axis [9], make it possible to conclude that the neutral axis displacement effect is insignificant and for the parameter $\psi<0.2$, typical for frame structures is no more than $3 \%$ relative to the area of an I-beam with a constant wall thickness. Consequently, for the design of frame elements of variable cross-section, it is irrational to use I-beams with different wall thicknesses, complicating the technological process of welding various walls. Also, the presence of a longitudinal compressive force significantly affects an increase in the symmetrical I-section flanges area, therefore, with $0.05<\psi<0.1$ it becomes rational to use monosymmetric Ibeams with a developed compressed flange.

In domestic series, rolled I-beams of the same section are used as compressed and stretched belts of posts and crossbars of frames. Taking into account the above-presented provisions, it is proposed to use rolled I-beams of different profiles, having different flange areas, with diagonal wall dissolving and subsequent welding. 
The assembly of rolled I-beams is performed by complying a longitude vertical joint in one-sided mechanized way on a flux cushion. It is allowed to perform the above-mentioned joints in a mechanized way in the environment $\mathrm{CO} 2$ one-sided (to a depth of at least half of the I-beams thickness), with the exception of the areas in the drop apron sections of the frames, where the vertical joints must be double-sided (at a length of $1000 \mathrm{~mm}$ in the frame racks and $1500 \mathrm{~mm}$ in the frames' crossbars). This requirement imposes restrictions on the I-beam assortment various positions applicability. The elements to be welded on opposite sides of the butt joint must have the same wall thickness. According to this requirement, the possible sections of I-beams are grouped by Industry Standard Association of Enterprises and Organizations for Standardization of Ferrous Metallurgy Products 20-93, for the prefabricated element design of a frame of variable stiffness with a constant wall thickness (Table 1).

\section{Research results}

It is rational to use rolling I-beams located at opposite positions of the group in designing the pre-fabricated element. As a rule, columnar and wide-flange I-beams have a more developed width and thickness of the flanges, which allows them to be used in the compressed zone of a frame element. In a situation in which one rolled profile has a large flange width, but a smaller flange thickness than another rolled profile from the group, an Ibeam with a larger flange thickness is preferred as an element of the compressed zone, due to its increased influence on the section resistance moment.

Table 1. The possible sections of I-beams are grouped by Industry Standard Association of Enterprises and Organizations for Standardization of Ferrous Metallurgy Products 20-93

\begin{tabular}{|c|c|c|c|c|}
\hline $\begin{array}{l}\text { Cross } \\
\text { section }\end{array}$ & $\begin{array}{c}\text { Section } \\
\text { height, mm }\end{array}$ & $\begin{array}{c}\text { Flange width, } \\
\text { mm }\end{array}$ & $\begin{array}{c}\text { Wall } \\
\text { thickness, mm }\end{array}$ & Flange thickness, $\mathrm{mm}$ \\
\hline 40B2 & 400,000 & 200,000 & \multirow{6}{*}{8,000} & 13,000 \\
\hline $45 \mathrm{~B} 1$ & 446,000 & 199,000 & & 12,000 \\
\hline 30Sh1 & 294,000 & 200,000 & & 12,000 \\
\hline $35 \mathrm{Sh} 1$ & 334,000 & 249,000 & & 11,000 \\
\hline $20 \mathrm{~K} 2$ & 200,000 & 200,000 & & 12,000 \\
\hline $25 \mathrm{~K} 1$ & 246,000 & 249,000 & & 12,000 \\
\hline $45 \mathrm{~B} 2$ & 450,000 & 200,000 & \multirow{6}{*}{9,000} & 14,000 \\
\hline $50 \mathrm{~B} 2$ & 496,000 & 199,000 & & 14,000 \\
\hline $30 \mathrm{Sh} 2$ & 300,000 & 201,000 & & 15,000 \\
\hline $35 \mathrm{Sh} 2$ & 340,000 & 250,000 & & 14,000 \\
\hline $25 \mathrm{~K} 2$ & 250,000 & 250,000 & & 14,000 \\
\hline $30 \mathrm{~K} 1$ & 298,000 & 299,000 & & 14,000 \\
\hline $55 \mathrm{~B} 1$ & 543,000 & 220,000 & \multirow{2}{*}{9,500} & 13,500 \\
\hline 40Sh1 & 383,000 & 299,000 & & 12,500 \\
\hline $50 \mathrm{~B} 3$ & 500,000 & 200,000 & \multirow{4}{*}{10,000} & 16,000 \\
\hline $55 \mathrm{~B} 2$ & 547,000 & 220,000 & & 15,500 \\
\hline $60 \mathrm{~B} 1$ & 596,000 & 199,000 & & 15,000 \\
\hline $40 \mathrm{Sh} 2$ & 390,000 & 300,000 & & 16,000 \\
\hline
\end{tabular}




\begin{tabular}{|c|c|c|c|c|}
\hline $25 \mathrm{~K} 3$ & 253,000 & 251,000 & & 15,500 \\
\hline $30 \mathrm{~K} 2$ & 300,000 & 300,000 & & 15,000 \\
\hline $35 \mathrm{~K} 1$ & 342,000 & 348,000 & & 15,000 \\
\hline $60 \mathrm{~B} 2$ & 600,000 & 200,000 & \multirow{5}{*}{11,000} & 17,000 \\
\hline 45Sh1 & 440,000 & 300,000 & & 18,000 \\
\hline 50Sh1 & 482,000 & 300,000 & & 15,000 \\
\hline $30 \mathrm{~K} 4$ & 304,000 & 301,000 & & 17,000 \\
\hline $40 \mathrm{~K} 1$ & 394,000 & 398,000 & & 18,000 \\
\hline 70B1 & 691,000 & 260,000 & \multirow{3}{*}{12,000} & 15,500 \\
\hline 60Sh1 & 582,000 & 300,000 & & 17,000 \\
\hline $35 \mathrm{~K} 2$ & 350,000 & 350,000 & & 19,000 \\
\hline
\end{tabular}

So, with the required wall thickness of an $I$-beam with a variable cross-section of $8 \mathrm{~mm}$, it is rational to use an $I$-beam as a product for designing a belt of a compressed zone $25 \mathrm{~K} 2$, for the extended zone $30 \mathrm{SH} 1$ or $40 \mathrm{~B} 2$. In this case, it is necessary to check whether the selected pair of $I$-beams will be enough to construct a section of the required height.

As an object of research, the frame of the building, designed according to the web-beam scheme from welded single-span frames with variable cross-section elements in accordance with standard cipher solutions $828 \mathrm{KM}$, was chosen. Frames with rigid upper nodes and a flange connection in the fastigium are pivotally supported on the foundation at an elevation $150 \mathrm{~mm}$. The frames are gable, the slope of the crossbars is $10 \%$. In the original project, the crossbars and posts are obtained by unreeling (along an inclined line) the $I$-beams 50 B2 and 55 B2 according to GOST $26020-83$ for the brands with their subsequent tilting on $180^{\circ}$ and welding. High-strength bolted frame joints M24 of steel 40X «Select» are used. Frame span $24 \mathrm{~m}$; frame pitch $6 \mathrm{~m}$; crossbar top mark +8.145 . The frames are equipped with girders made of rolled profiles, which in the outer spans work according to a two-span scheme with the support on spacers along the half-timbered posts.

The cross-frame is divided into three starting marks. The central part of the frame crossbar is made of a variable section beam with a maximum height at the building fastigium. The part of the frame crossbar adjacent to the cornice unit is made with a separate pre-fabricated mark with the maximum section height in the area of the cornice unit. The frame post is made with a separate pre-fabricated mark, the connection with the crossbar is made by means of a flange connection (Fig. 1).

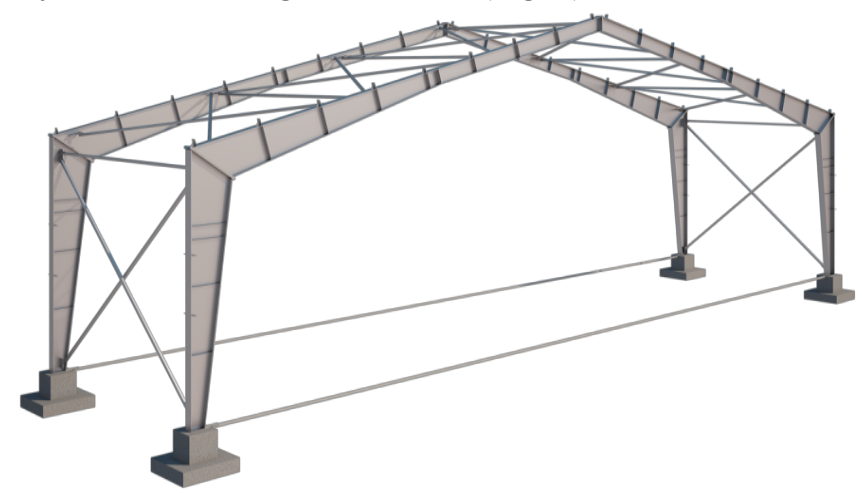

Fig. 1. Model of a transverse frame made of variable I-beams section. 
Loads from the roofing, snow and wind loads are applied to the transverse frame of the frame. Calculation of efforts was performed in the SCAD Office software package based on the finite element method [8].

The preliminary dimensions of finite elements are assigned in accordance with the standard series used in the frames design of such spans. The foundation support is modeled hingedly, the girders and pillars are divided into rod finite elements up to $2 \mathrm{~m}$ long.

The most optimal placement of the flange connection in the frame girder is located at a distance of $4 \mathrm{~m}$ from the eaves gutter assembly at the zero bending moment point. The calculation of the frame elements was carried out according to the formulas [1.5] in the following sequence:

1) Calculation of the initial coefficients taking into account the influence of shear stresses from the action of shear forces on the beam web stability, taking into account the stiffeners arrangement:

$$
k_{\tau 0}=1.316 \cdot Q \cdot 3 \cdot \sqrt{\frac{\lambda_{0}}{M^{2} \cdot R_{y}}}, k_{a 0}=\frac{1}{a} \cdot \sqrt[3]{\frac{M \cdot \lambda_{0}}{R_{y}}}
$$

as well as the calculation of a parameter that takes into account the contribution of stresses from the longitudinal force to the work of the structure:

$$
\psi=\frac{3}{8} \cdot N \cdot \sqrt[3]{\frac{\lambda_{0}}{M^{2} \cdot R_{y}}}
$$

where $M, N, Q$ are design forces in the element, $\lambda_{0}$ denotes initial flexibility of the element, $R_{y}$ is design steel resistance, $a$ is stiffener spacing.

2) Calculation of the required moment of resistance (according to the formula 41 [6]):

$$
W_{M}=\frac{M}{R_{y} \cdot \gamma_{c} \cdot c_{x}}
$$

3) Determination of the initial limiting flexibility of the wall:

$$
\lambda_{u 0}=\frac{6 \cdot(1-0,5 \cdot \psi) \cdot \delta_{\lambda}}{\sqrt[4]{1+12 \cdot\left(\frac{k_{\tau 0}}{1+0.76 \cdot k_{a 0}}\right)^{2}}} \cdot k_{r}
$$

where $\delta_{\lambda}=1$ is the coefficient for I-beams with a stable wall, presented in the range of rolled products.

3) Determination of the optimal section height for I-beams with a stable wall:

$$
h_{\text {opt }, \text { mono }}=\sqrt[3]{\frac{3}{2} \cdot W_{M} \cdot \lambda_{w 0}}
$$

4) Section height assignment $h_{w}$ taking into account I-beam optimal cutting, structural and other requirements. Wall thickness assignment $t_{w}$, depending on the assigned wall flexibility.

5) Determining the area of the flanges: 
Compressed flange area: $A_{1 e f}=\frac{W_{M}}{(1-\psi) \cdot h_{w}}-\frac{t_{w} \cdot h_{w}}{6} \cdot \frac{1-3 \psi}{1-\psi} \cdot \delta_{w}$

Stretched flange area: $A_{1 e f}=\frac{W_{M}}{(1+\psi) \cdot h_{w}}-\frac{t_{w} \cdot h_{w}}{6} \cdot \frac{1+3 \psi}{1+\psi} \cdot \delta_{w}$

where $\delta_{w}=1$ is the coefficient for $I$-beams with a stable wall, presented in the range of rolled products.

7) Determination of the calculated thickness and width of the flanges:

$$
t_{i e f}=\delta_{f} \cdot \sqrt{\frac{A_{i e f}}{k_{r}}}, b_{i e f}=\frac{A_{i e f}}{t_{i e f}}
$$

\section{Conclusion}

The performed calculations showed that the use of different positions of the assortment for unreeling and subsequent welding made it possible to reduce the variable section element mass in comparison with the I-beams of the same standard size used in the series. The difference in metal consumption was $15.7 \%$, which allows us to conclude that the use of the elements of variable cross-section formed by $I$-beams diagonal dissolution of various crosssections in the construction of industrial frame buildings is a promising direction for investigation.

\section{References}

1. V.V. Katyushin, Buildings with frames made of steel frames of variable cross-section, Monograph (Publishing house ASV, Moscow, 2018).

2. N.P. Abovskiy, Selected problems in structural mechanics and elasticity theory (Stroyizdat, Moscow, 1978).

3. B.I. Balyayev, Optimization of cross-sections of beams with chords of rolled tees and a web of sheet steel. Manufacturing of metal and installation of building structures. Express information, Minmontajspezstroy, Issue. 4, USSR, Moscow, 1990.

4. Ya.L. Kaplun, Optimization of the assortment of rolled profiles, PhD Thesis summary, (Science, Moscow, 1971).

5. Central Research Institute of Building Structures named after Kucherenko Gosstroy of the USSR, A guide to the design of steel structures (Stroyizdat, Moscow, 1989).

6. Building Codes "Steel structures". BC 16.13330.2017. Central Research Institute of Building Structures named after Kucherenko.

7. V.V. Kuznetsov, Designer handbook, vol. 3 (ASV, Moscow, 1999).

8. A.A. Alyamovskiy, Solid works, Cosmos Works: finite element analysis (DMK, Moscow, 2004).

9. Yu.V. Sobolyev, Construction and architecture 1, 18-21 (1985).

10. Information on htps: // www.vedomosti.ru /realty /articles /2020/02/16/ 823152zhilischnoe-stroitelstvo. Date of access 16.03.2021. 
11. S.V. Skachkov, Solving the problem of optimizing the design parameters of beveling trusses with T-belts, Lightweight building structures: Collection of scientific papers (Rostov-on-Don, Rostov State University of Civil Engineering, 1999).

12. A.O. Zaprosyan, Optimization of sections of welded poly-beams, Lightweight building structures (Collection of scientific papers, Rostov-on-Don, 1993). 